\title{
Do Patients in a Primary Care Practice Know the Current Cancer Screening Guidelines?
}

\author{
Neil D’Souza, Morgan Slater, Aisha Lofters* \\ Department of Family and Community Medicine, St. Michael's Hospital-University of Toronto, Toronto, \\ Canada \\ Email: ${ }^{*}$ aisha.lofters@utoronto.ca
}

Received 18 March 2014; revised 3 May 2014; accepted 16 May 2014

Copyright (C) 2014 by authors and Scientific Research Publishing Inc.

This work is licensed under the Creative Commons Attribution International License (CC BY). http://creativecommons.org/licenses/by/4.0/

(c) (7) Open Access

\section{Abstract}

Background: In spite of supporting evidence and widespread promotional campaigns, screening rates for breast, cervical and colorectal cancers in Ontario are lower than expected. These low screening rates may be partially due to lack of knowledge on the part of patients. Given the importance of early detection to reduce cancer mortality and morbidity, it is prudent to investigate where knowledge deficits may exist. The purpose of this study was to assess patient knowledge of the Ontario screening guidelines for breast, cervical and colorectal cancers. Methods: Patients of a family health team in Toronto, Ontario were surveyed regarding their knowledge of cancer screening guidelines. Questions included knowledge regarding the test, screening interval and age for cancer screening for breast, cervical and colorectal cancers as well as sociodemographic characteristics. Responses were summarized using descriptive statistics. Results: A total of 117 patients were surveyed. Knowledge of the appropriate screening test was high for breast and cervical cancer $(85.5 \%$ and $70.1 \%$ respectively) though much lower for colorectal cancer $(17.1 \%)$. Knowledge regarding the age that screening should occur and the screening intervals were much lower across all cancer types. For breast cancer, $16.2 \%$ knew the age screening should occur and $30.8 \%$ knew the screening interval. For cervical cancer, $6.8 \%$ knew the age screening should occur and only $4.3 \%$ knew the screening interval. For colorectal cancer, $32.5 \%$ knew the age to start screening and $26 \%$ knew the screening interval. Conclusions: Knowledge of the cancer screening guidelines appeared to be low across all cancer types, particularly for the ages at when screening should occur and the appropriate screening intervals. These results suggest that public health practitioners and cancer prevention organizations may need to increase efforts for patient education on cancer screening.

*Corresponding author. 


\section{Keywords}

\section{Cancer Screening, Health Promotion, Illness Prevention}

\section{Introduction}

The Canadian Cancer Society estimates that over 187,000 people will have been diagnosed with and over 75,500 people will have died of cancer by the end of 2013 [1]. Cancer Care Ontario (CCO), the agency responsible for leading provincial cancer care efforts, has developed cancer screening programs for early detection of cancers presenting significant population burden, namely breast, cervical and colorectal cancers. The intent is to decrease cancer morbidity and mortality along all phases of the cancer care pathway. In spite of these efforts, provincial data indicate that screening rates remain low. Breast cancer screening rates in 2010-2011 were only $61 \%$ [2] and cervical cancer screening rates in 2009-2011 were only 65\% [3]. Colorectal cancer (CRC) screening rates in 2010-2011 were 53\%, with only $30 \%$ of eligible Ontarians having the preferred test-the fecal occult blood test (FOBT) [4].

The reasons for the lower-than-desired screening rates are not entirely clear; however, evidence supports socioeconomic status as a contributing factor. For example, women who are immigrants, older and of lower socioeconomic status report lower rates of cervical cancer screening [5]-[7]. People of low income, low education, recent immigrants and certain ethnic groups have been found to have lower CRC screening rates, and women with mental illness, homelessness or substance abuse utilize screening mammography less often [8]-[11]. Arguments have also been made for the lack of knowledge regarding preventive health practices or inability to navigate the medical system [12] [13]. For example, the Canadian Cancer Society has reported that breast cancer screening guidelines can be confusing for women [14].

Therefore, it is important to gain a sense of what baseline knowledge exists, especially among populations where low socioeconomic status may be prevalent. Thus, the purpose of this study was to assess the overall knowledge of the Ontario screening guidelines for breast, cervical and colorectal cancers among a diverse group of patients of a large, urban family health team.

\section{Methods}

We surveyed patients of a large, academic, urban family practice located in Toronto, Ontario. The patient population this practice serves is diverse, with varying socioeconomic, cultural, language, religious and ethnic backgrounds. Particular focus is also placed on inner city health issues associated with homeless, disadvantaged and vulnerable individuals. Patients were approached in the waiting room using convenience sampling. The survey was provided to any patient who appeared to be screen-eligible (based on age) for any or all of the three evidence-supported forms of cancer screening. The survey was comprised of: 1) nine questions regarding knowledge of the three evidence-supported guidelines of cancer screening in Ontario (one question each on method, frequency and ages of screening) in a multiple choice format; and 2) nine sociodemographic questions. The survey was anonymous; no personal identifiers were collected. Upon completion of the survey, an information sheet was given out to all participants outlining the current screening guidelines in Ontario.

Data were summarized using descriptive statistics. Analysis of correct responses was determined by comparing the participant survey answers to current screening guidelines. We also analyzed correct responses within at risk populations as follows: 1) breast cancer-females, aged 50 - 69; 2) cervical cancer-all females surveyed; 3) colorectal cancer-all males and females, aged 50 and over. These categories were used as liberal estimates of respondents who would be eligible for each screening type.

This study received ethics approval from the Research Ethics Board (REB) at St. Michael’s Hospital.

\section{Results}

A total of 117 patients completed surveys. The majority of respondents were women (76.1\%) and 58\% of respondents were over 50 years of age (Table 1). Most individuals had a post-secondary education (77.8\%), but $74.8 \%$ of participants assessed their financial status as "struggle to get by" or "just enough". Just over $37 \%$ were foreign-born and $35.4 \%$ were visible minorities. Most participants rated their health as "very good" (36.3\%) or "good" (38.1\%). 
Table 1. Respondent demographics $(n=117)$.

\begin{tabular}{|c|c|}
\hline Demographic & N (\%) \\
\hline \multicolumn{2}{|l|}{ Age } \\
\hline$<50$ & $47(42.0)$ \\
\hline $50-54$ & $11(9.8)$ \\
\hline $55-59$ & $11(9.8)$ \\
\hline $60-64$ & $14(12.5)$ \\
\hline $65-69$ & $16(14.3)$ \\
\hline $70-74$ & $6(5.4)$ \\
\hline$>75$ & $7(6.3)$ \\
\hline \multicolumn{2}{|l|}{ Gender } \\
\hline Female & $86(76.1)$ \\
\hline Male & 27 (23.9) \\
\hline \multicolumn{2}{|l|}{ Marital status } \\
\hline Married/partnered & $57(50.0)$ \\
\hline Separated/divorced & $14(12.3)$ \\
\hline Widowed & $12(10.5)$ \\
\hline Single, never married & $31(27.2)$ \\
\hline \multicolumn{2}{|l|}{ Length of time in Canada } \\
\hline$<5$ years & $2(1.8)$ \\
\hline 5 - 10 years & $8(7.0)$ \\
\hline$>10$ years & $33(28.9)$ \\
\hline All my life & $71(62.3)$ \\
\hline \multicolumn{2}{|l|}{ Language } \\
\hline English & $95(84.1)$ \\
\hline French & $2(1.8)$ \\
\hline Other & $16(14.1)$ \\
\hline \multicolumn{2}{|l|}{ Race } \\
\hline Caucasian & $73(64.6)$ \\
\hline Non-Caucasian & $40(35.4)$ \\
\hline \multicolumn{2}{|c|}{ Highest level of education completed } \\
\hline Less than high school & $9(8.0)$ \\
\hline High school & $16(14.2)$ \\
\hline College/university & $88(77.8)$ \\
\hline \multicolumn{2}{|l|}{ Perceived financial status } \\
\hline More than enough & $28(25.2)$ \\
\hline Just enough & $66(59.5)$ \\
\hline Struggle to get by & $17(15.3)$ \\
\hline \multicolumn{2}{|l|}{ Self-rated health } \\
\hline Excellent & $8(7.1)$ \\
\hline Very good & $41(36.3)$ \\
\hline Good & $43(38.1)$ \\
\hline Fair & $17(15.0)$ \\
\hline Poor & $4(3.5)$ \\
\hline
\end{tabular}


Most respondents (85.5\%) knew that a mammogram was the recommended screening test for breast cancer (Table 2, Figure 1). However, only $16.2 \%$ of respondents knew the age at which screening should occur and $30.8 \%$ correctly knew the frequency of testing. Similar results were observed for cervical cancer, where $70.1 \%$ correctly identified the Pap test as the screening tool. However, only $6.8 \%$ of respondents knew the age at which screening should occur and an even smaller proportion (4.3\%) knew the frequency of testing. For colorectal cancer; only $17.1 \%$ knew that FOBT was the screening test of choice, $32.5 \%$ correctly identified the starting age for screening and $26.5 \%$ knew the frequency of testing.

Among women assumed to be eligible for breast cancer screening (ages 50 - 69), 88.9\% knew the correct screening test, $16.7 \%$ knew the correct ages, and $47.2 \%$ knew the correct screening interval (Figure 2). Only 5 respondents (13.9\%) answered all three questions correctly and 33 (91.7\%) individuals had at least one correct response Among women assumed to be eligible for cervical cancer screening (all women regardless of age), $11.6 \%$ knew the correct screening test, $10.5 \%$ knew the correct ages, and 5.8\% knew the correct screening interval (Figure 2). Seventy-two individuals (83.7\%) had at least one correct response, however only 1 respondent answered all three questions correctly. Finally, among respondents assumed to be eligible for colorectal cancer screening (all men and women over the age of 50), 26.5\% knew the correct screening test, 33.8\% knew the correct ages, and 26.1\% knew the correct screening interval (Figure 2). Forty individuals (61.5\%) had at least one response correct and only 3 respondents answered all three questions correctly.

\section{Discussion}

Overall, knowledge of cancer screening guidelines in this study was low, especially for cervical and colorectal cancers where the incorrect responses were greater in number and proportion to correct responses. In addition, knowledge of when to start screening and how often screening should occur also appeared low across all cancer types. The one exception where knowledge appeared to be high was for breast cancer, where the majority of individuals correctly answered that mammograms were the recommended screening test. We also stratified responses according to screening eligibility for each cancer type and despite small numbers, the findings yielded similar results: overall knowledge of cancer screening guidelines appeared to be low.

Our results are similar to other Canadian studies found in the literature, where overall cancer screening knowledge was low [15]-[18]. Vahabi et al. found that breast health knowledge was limited among 180 young women in Toronto [15]. A second Vahabi study conducted among 50 Iranian immigrant women showed that participants had limited knowledge of breast cancer and screening practices [16]. Hislop et al. conducted a community-based survey in British Columbia and found that knowledge about cervical cancer risk factors was low among Chinese-Canadian women [17]. However, these studies focused on specific populations with respect to age, ethnicity and practice setting, and used different means to evaluate knowledge. To our knowledge, the findings from this study represent the first to use age, test type and frequency as proxies to assess cancer screening knowledge for the three evidenced-based cancer screening guidelines in Ontario.

These findings of patient knowledge deficit, including among those who are screen-eligible, are intriguing as they suggest that there is room for improvement in terms of how health care organizations, health professionals and health ministries educate the public and promote screening programs. One study notes that colorectal cancer screening was low among older Canadians due to reasons such as physician screening recommendations, surprising colorectal cancer information and difficulties understanding cancer information [19]. In addition, cancer screening guidelines themselves may be confusing due to changes reflecting new evidence [14]. This confusion may have an impact on knowledge. Further, patients may not necessarily know what the screening test actually is in comparison to other health examinations performed during a physician visit (e.g. what a pap smear is used for versus a pelvic exam). As such, the issue of patients' deficit in cancer screening knowledge may not necessarily lie with the patient; overall health care knowledge deficits may exist because health care providers, upon which many patients rely for information, are not providing the needed education and information [20]. Our results suggest that improved public education is especially needed for cervical and colorectal cancers.

\subsection{Study Limitations}

While study findings suggest that knowledge of the cancer screening guidelines are low, one must keep in mind the limitations of this study. First, our survey was not validated. However, we strove to keep the survey brief and to use language that was as simple and clear as possible. Second, since convenience sampling was used, the 
Table 2. Knowledge of current Ontario cancer screening guidelines (n = 117).

\begin{tabular}{|c|c|}
\hline \multicolumn{1}{|c|}{ Breast cancer } & N (\%) \\
\hline Screening test & \\
\hline Ultrasound & $1(0.9)$ \\
MRI & $2(1.7)$
\end{tabular}

Mammogram

Breast exam by doctor or nurse

Unsure/don't know

Ages for testing

$$
20-74
$$

$30-74$

$40-74$

50 - 69

Unsure/don’t know

Frequency of testing

Every 6 months

Every 1 year

Every 2 years

Every 3 years

Unsure/don’t know

\section{Cervical cancer}

Screening test

Fecal occult blood test

Pap test

82 (70.1)

Pelvic ultrasounds

Pelvic exam

Unsure/don’t know

\begin{tabular}{|c|c|}
\hline Unsure/don’t know & $20(17.1)$ \\
\hline \multicolumn{2}{|l|}{ Ages for starting testing } \\
\hline At least 18 years old and ever been sexually active & $52(44.4)$ \\
\hline At least 21 years old and ever been sexually active & $8(6.8)$ \\
\hline 21 years old, regardless of sexual activity & $17(14.5)$ \\
\hline At least 25 years old, regardless of sexual activity & $17(14.5)$ \\
\hline Unsure/don’t know & $22(18.8)$ \\
\hline \multicolumn{2}{|l|}{ Frequency of testing } \\
\hline Every 6 months & $4(3.4)$ \\
\hline Every 1 year & $67(57.3)$ \\
\hline Every 2 years & $19(16.2)$ \\
\hline Every 3 years & $5(4.3)$ \\
\hline Unsure/don’t know & $22(18.8)$ \\
\hline
\end{tabular}




\begin{tabular}{|c|c|}
\hline \multicolumn{2}{|c|}{ Colorectal cancer } \\
\hline Screening test & \\
\hline Fecal occult blood test & $20(17.1)$ \\
\hline Rectal exam & $10(8.6)$ \\
\hline Abdominal ultrasound & $2(1.7)$ \\
\hline Colonoscopy & $64(54.7)$ \\
\hline Unsure/don't know & $21(18.0)$ \\
\hline \multicolumn{2}{|l|}{ Age to start testing } \\
\hline 40 years & $48(41.0)$ \\
\hline 45 years & $11(9.4)$ \\
\hline 50 years & 38 (32.5) \\
\hline 55 years & $5(4.3)$ \\
\hline Unsure/don't know & $15(12.8)$ \\
\hline \multicolumn{2}{|l|}{ Frequency of testing } \\
\hline Every 1 year & $36(30.8)$ \\
\hline Every 2 years & 31 (26.5) \\
\hline Every 3 years & $19(16.2)$ \\
\hline Every 10 years & $5(4.3)$ \\
\hline Unsure/don't know & $25(21.4)$ \\
\hline
\end{tabular}

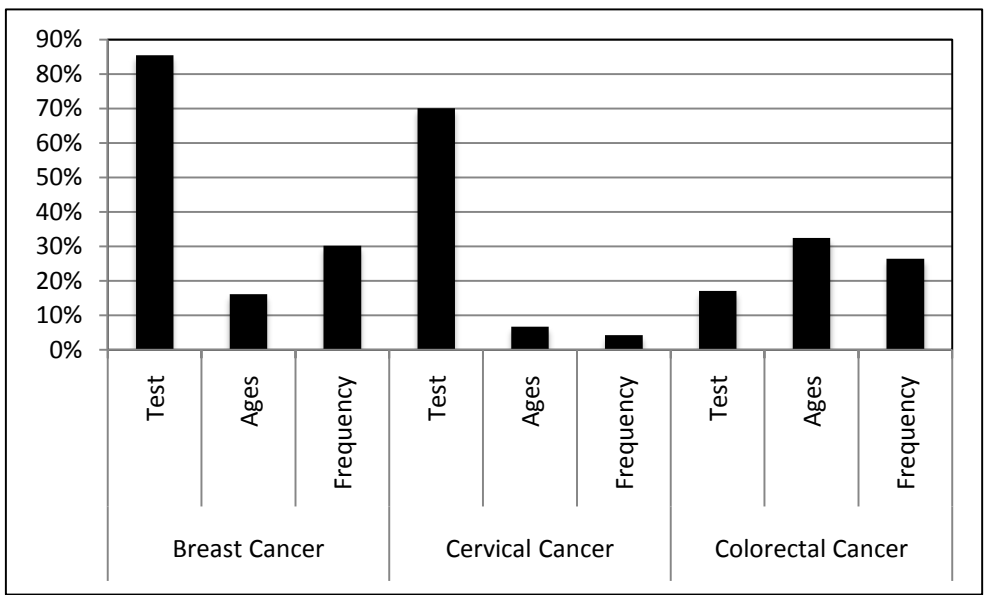

Figure 1. Proportion of correct responses.

study population may not be entirely representative and in turn, may lead to bias in study findings. Third, patients were approached based on visual estimation of age. Therefore, some eligible patients in the waiting room might have been missed based on appearance. However, considering the broad age range, the number of patients missed is likely to be low. Lastly, the sample size $(\mathrm{N}=117)$ may not be large enough to draw conclusions generalizable to the broader population.

\subsection{Future Directions}

Possible next steps would be to further study the degree of knowledge among patients who are screen-eligible 


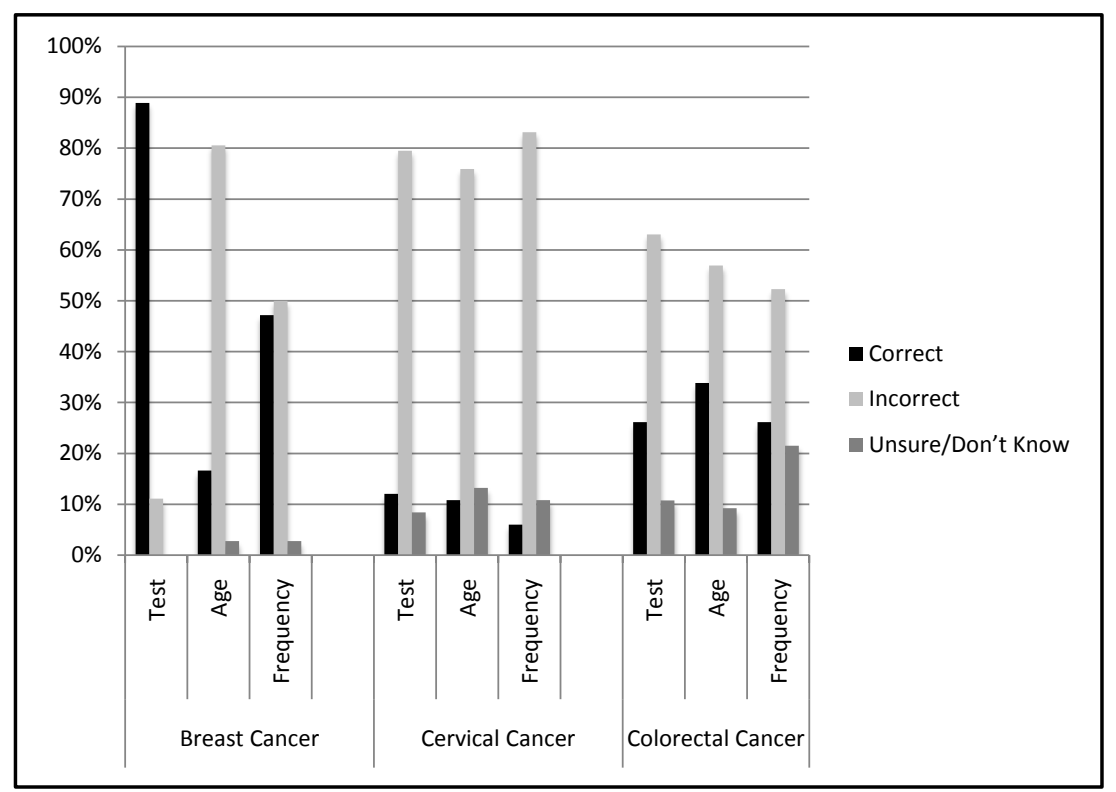

Figure 2. Response distribution for breast, cervical and colorectal screening for participants assumed to be eligible for screening.

and if this is directly related to screening rates. In addition, exploring factors that are associated with decreased level of knowledge among screen eligible patients (e.g. socioeconomic status) would also be an important future direction. In turn, these results could further yield how to make screening materials more appropriate for patients and whether such changes would ultimately yield higher screening rates.

\section{Conclusion}

The findings from this study suggest overall knowledge, based on age, screening test type and frequency of screening, of Ontario's screening guidelines for breast, cervical and colorectal cancers appear to be low. Further study is needed to discern underlying reasons for this low knowledge level and in turn, what strategies can be used for improvement.

\section{References}

[1] Canadian Cancer Society (2014) General Statistics. Canada. http://www.cancer.ca/en/cancer-information/cancer-101/canadian-cancer-statistics-publication/?region=bc

[2] Cancer Quality Council of Ontario (2014) Breast Cancer Screening: Participation. http://www.csqi.on.ca/cms/one.aspx?portalId=258922\&pageId=273161\#.UovBzJF7gxB

[3] Cancer Quality Council of Ontario (2014) Cervical Cancer Screening: Participation. http://www.csqi.on.ca/cms/One.aspx?portalId=258922\&pageId=273194\#.UovCM5F7gxA

[4] Cancer Quality Council of Ontario (2014) Colorectal Cancer Screening: Participation. http://www.csqi.on.ca/cms/One.aspx?portalId=258922\&pageId=273238\#.UovCX5F7gxC

[5] McDonald, J.T. and Kennedy, S. (2007) Cervical Cancer Screening by Immigrant and Minority Women in Canada. Journal of Immigrant and Minority Health, 9, 323-334. http://dx.doi.org/10.1007/s10903-007-9046-X

[6] Maxwell, C.J., Bancej, C.M., Snider, J., et al. (2001) Factors Important in Promoting Cervical Cancer Screening among Canadian Women: Findings from the 1996-97 National Population Health Survey (NPHS). Canadian Journal of Public Health, 92, 127-133.

[7] Lofters, A.K., Moineddin, R., Hwang, S.W. and Glazier, R.H. (2010) Low Rates of Cervical Cancer Screening among Urban Immigrants: A Population-Based Study in Ontario, Canada. Medical Care, 48, 611-618. http://dx.doi.org/10.1097/MLR.0b013e3181d6886f

[8] Centers for Disease Control and Prevention (2008) Vital Signs: Colorectal Cancer Screening among Adults Aged 50-75 Years-United States. MMWR, 59, 808-812. 
[9] Shapiro, J.A., Seeff, L.C., Thompson, T.D., Nadel, M.R., Klabunde, C.N. and Vernon, S.W. (2008) Colorectal Cancer Test Use from the 2005 National Health Interview Survey. Cancer Epidemiology, Biomarkers \& Prevention, 17, 16231630. http://dx.doi.org/10.1158/1055-9965.EPI-07-2838

[10] Seeff, L.C., Nadel, M.R., Klabunde, C.N., Thompson, T., Shapiro, J.A., Vernon, S.W., et al. (2004) Patterns and Predictors of Colorectal Cancer Test Use in the Adult U.S. Population. Cancer, 100, 2093-2103. http://dx.doi.org/10.1002/cncr.20276

[11] Heyding, R.K., Cheung, A.M., Mocarski, E.J., Moineddin, R. and Hwang, S.W. (2005) A Community-Based Intervention to Increase Screening Mammography among Disadvantaged Women at an Inner-City Drop-In Center. Women's Health, 41, 21-31. http://dx.doi.org/10.1300/J013v41n01 02

[12] Ahmad, F., Cameron, J.I. and Stewart, D.E. (2005) A Tailored Intervention to Promote Breast Cancer Screening Amount South Asian Immigrant Women. Social Science \& Medicine, 60, 575-586. http://dx.doi.org/10.1016/j.socscimed.2004.05.018

[13] Bardach, S.H., Schoenberg, N.E., Fleming, S.T. and Hatcher, J. (2012) Relationship between Colorectal Cancer Screening Adherence and Knowledge among Vulnerable Rural Residents of Appalachian Kentucky. Cancer Nursing, 35, 288-294. http://dx.doi.org/10.1097/NCC.0b013e31822e7859

[14] Canadian Cancer Society (2012) Cutting through the Breast Cancer Confusion: Canadian Cancer Society Finds Majority of Ontario Women Are Still Confused about Breast Cancer Screening: Ipsos Reid Poll. Ontario. http://www.cancer.ca/Ontario/About\%20us/Media\%20centre/OD-MediaReleases2012/Cutting\%20through\%20the\%20 breast\%20cancer\%20confusion.aspx?sc_lang=en

[15] Vahabi, M. (2005) Knowledge of Breast Cancer and Screening Practices. Health Education Journal, 64, 218-228. http://dx.doi.org/10.1177/001789690506400303

[16] Vahabi, M. (2011) Knowledge of Breast Cancer and Screening Practices among Iranian Immigrant Women in Toronto. Journal of Community Health, 36, 265-277. http://dx.doi.org/10.1007/s10900-010-9307-9

[17] Hislop, T.G., Chong, T., Lai, A., Ralston, J.D., Shu, J. and Taylor, V.M. (2004) Pap Screening and Knowledge of Risk Factors for Cervical Cancer in Chinese Women in British Columbia, Canada. Ethnicity \& Health, 9, 267-281. http://dx.doi.org/10.1080/1355785042000250102

[18] Wayne, K. (2011) Colorectal Cancer Screening Rates Lagging. CMAJ, 83, E647-E648.

[19] Hoffman-Goetx, L., Thomson, M.D. and Donelle, L. (2008) Reasons for Declining Colorectal Cancer Screening by Older Canadians: A Pilot Study. Journal of Cancer Education, 23, 32-36. http://dx.doi.org/10.1080/08858190701821188

[20] Meissner, H.I., Potosky, A.L. and Convissor, R. (1992) How Sources of Health Information Related to Knowledge and Use of Cancer Screening Exam. Journal of Community Health, 17, 153-165. http://dx.doi.org/10.1007/BF01324404 